\title{
2020: UN AÑO DE GRANDES RETOS Y OPORTUNIDADES
}

\author{
2020: A YEAR OF GREAT CHALLENGES AND OPPORTUNITIES
}

Jhony A. De La Cruz-Vargas ${ }^{1, a, b, c}$

Iniciar el año 2020 con la publicación del primer numero de la Revista de la Facultad de Medicina Humana, es refrescante e inspirador. El año 2019 quedó atrás, significó un año de grandes logros e indizaciones para nuestra Revista. Este nuevo año nos abre la posibilidad de profundizar y avanzar en la calidad de las publicaciones, así como en diversificar e internacionalizar las colaboraciones.

Nuestro principal agradecimiento al Rector de la Universidad Ricardo Palma, el Dr. Elio Iván Rodríguez Chávez, por todo su apoyo y visión para guiar la Revista.

De manera especial damos la bienvenida a nuestros "Editores Invitados Internacionales", el Profesor Dr. Antonio Russo, de la Università degli studi di Palermo, Italia nos trae una interesante y actual editorial sobre "la Biopsia Líquida", ¿Mito o Realidad?; abordando un tema de punta de lanza en el diagnóstico, pronóstico y tratamiento de pacientes con cáncer. El Dr. Russo con un enfoque práctico y actual comparte con nosotros su experiencia y los avances en esta nueva era del diagnóstico del cáncer.

Por otro lado, es un gusto contar con el Dr. Marcus Tolentino-Silva de la Universidad de Sorocava, Brasil, quien plantea un tema absolutamente importante: Perspectivas de evaluaciones tecnológicas en salud.

Como Editor Invitado Nacional, el Dr. Willy Ramos Muñoz, quien recientemente publicó el libro: Análisis de la Situación del Cáncer en el Perú 2018, del Centro Nacional de Epidemiologia, Prevención y Control de Enfermedades del Ministerio de Salud, que será una herramienta poderosa en la toma de decisiones.

Nuestra Revista inicia el 2020 con un incremento del 50\% de artículos originales, su versión completa bilingüe: ingles y español, así como su reciente acceso a DIGITAL COMMONS de ELSEVIER, cumpliendo el compromiso de contribuir a la difusión de producción científica de calidad.

Una mirada rápida al índice del presente número nos muestra 17 artículos originales, tanto nacionales como internacionales, abordando diversos temas de salud publica y medicina, 03 artículos de revisión, 02 casos clínicos y 05 cartas al editor.

Invitamos a todos los lectores a continuar enviando sus trabajos para publicar en nuestra revista indizada.

Gracias a todo nuestro Comité Editorial, equipo de trabajo y colaboradores nacionales e internacionales; nuestro compromiso es continuar trabajando para que el 2020 sea un año de retos, exitos y oportunidades para todos. 